\title{
Retraction Note to: Morphological and Field Emission Properties of ZnO Deposited MWCNT by RF Sputtering and PECVD
}

\author{
P. Farazmand ${ }^{1} \cdot$ S. Fehli ${ }^{2} \cdot$ A. Salar Elahi ${ }^{3} \cdot$ M. Ghoranneviss ${ }^{3}$
}

Published online: 8 September 2017

(C) Springer Science+Business Media, LLC 2017

Retraction Note to: J Inorg Organomet Polym

(2015) 25:1470-1477

DOI 10.1007/s10904-015-0263-9

It has come to our attention that the abovementioned paper containing results and figures that have been copied from already published papers in violation of copyright laws and ethical standards of this journal and the scientific community. Therefore, this paper is retracted and should not be cited in the literature as original research.

The online version of the original article can be found under doi:10.1007/s10904-015-0263-9.

A. Salar Elahi

Salari_phy@yahoo.com

1 Department of Physics, Imam Khomeini University, Qazvin, Iran

2 Department of Physics, Shahed University, Tehran, Iran

3 Plasma Physics Research Center, Science and Research Branch, Islamic Azad University, Tehran, Iran 